Estudios sobre armas antiguas, arte militar $\mathrm{y}$ vida cultural en oriente y occidente

XL (2020), pp. 133-152

ISSN: 0436-029X; eISSN: 1988-4168

https://doi.org/10.3989/gladius.2020.06

\title{
ARMAMENTO Y ACCESORIOS MILITARES EN LA FORTALEZA MEDIEVAL DE MENDIKUTE (GUIPÚZCOA, PAÍS VASCO), SIGLOS XIII-XIV: UN ANÁLISIS MORFOLÓGICO Y FUNCIONAL*
}

\author{
WEAPONRY AND WAR ACCESSORIES AT THE MEDIEVAL FORTRESS OF MENDIKUTE \\ (GIPUZKOA, BASQUE COUNTRY), 13-14 ${ }^{\mathrm{TH}}$ CENTURIES: \\ A MORPHOLOGIC AND FUNCTIONAL ANALYSIS
}

POR

Karen Álvaro RuedA ${ }^{* *}$ y Esther Travé Allepuz ${ }^{* * *}$

\section{RESUMEN - ABSTRACT}

Las excavaciones arqueológicas en la fortaleza medieval de Mendikute (Albiztur, Guipúzcoa) permitieron recuperar una numerosa colección de materiales metálicos entre los que se cuentan un volumen considerable de restos de armamento. Este conjunto de material bélico, que incluye puntas de lanza, saetas y otros elementos no proyectiles como dagas, cuchillos y algunos útiles auxiliares de la actividad militar, ha sido documentado a lo largo de los últimos años y analizado desde una perspectiva morfológica y funcional a fin de definir una tipología precisa con base en datos morfométricos cuantificables. La colección presenta numerosos paralelos con otros ejemplares coetáneos y su interpretación con base en un registro arqueológico detallado ofrece valiosa información para el conocimiento de las prácticas militares de la Baja Edad Media.

A wide collection of metallic materials was discovered during the archaeological fieldwork at the medieval fortress of Mendikute (Albiztur, Gipuzkoa). Amongst these, there is a considerable amount of weapon fragments. This assemblage of weaponry includes spear fragments, arrows and other non-projectile elements such as daggers, knives or auxiliary tools for military activity. The collection has been documented during the last few years and approached by means of morphological and functional analyses, in order to define a precise typology based on quantifiable morphometric data. There are numerous parallels for these weapons in correlation with other contemporary specimens. Their interpretation built upon a detailed archaeological record offers valuable information for the knowledge of the military practices of the Late Middle Ages.

\section{Palabras Clave - Keywords}

Armamento; Baja Edad Media; País Vasco; lanza; flecha; tipología; fortificación.

Weaponry; Late Middle Age; Basque Country; spear; arrow; typology; fortress.

* El trabajo presentado se cuenta entre las tareas habituales del Grupo de Investigación en Arqueología Medieval y Post-Medieval de la Universidad de Barcelona (GRAMP.UB), reconocido y consolidado por la Generalitat de Catalunya (2017SGR-833-GRC). La excavación de Mendikute fue posible gracias a la realización de un proyecto titulado «Reorganización del espacio y estructura de poblamiento en la cuenca alta del río Oria (s. XI-XII, Guipúzcoa)», dirigido por el Dr. J. I. Padilla y financiado por la Diputación Foral de Guipúzcoa y el Gobierno Vasco.

** Universidad de Barcelona, Departamento de Historia y Arqueología, Grupo de investigación de Arqueología Medieval y Postmedieval (GRAMP.UB), kalvaro@ub.edu / ORCID iD: http://orcid.org/0000-0003-1321-7260

${ }^{* * *}$ Universidad de Barcelona. Departamento de Historia y Arqueología. Grupo de investigación de Arqueología Medieval y Postmedieval (GRAMP.UB), esther.trave@ub.edu / ORCID iD: http://orcid.org/0000-0002-6769-4487 


\section{Cómo CitAR eSte ARTículo / Citation}

Álvaro Rueda, K. y Travé Allepuz, E. (2020): «Armamento y accesorios militares en la fortaleza medieval de Mendikute (Guipúzcoa, País Vasco), siglos XIII-XIV: Un análisis morfológico y funcional». Gladius, 40: 133-152. https://doi.org/10.3989/gladius.2020.06

\section{INTRODUCCIÓN}

La excavación de la fortaleza medieval de Mendikute se prolongó durante seis campañas de intervención arqueológica (Padilla, 1993, 1994, 1995, 1996, 1997) y permitió afrontar el estudio de un yacimiento que puede ser considerado como un ejemplo elocuente del tipo de fortificaciones altomedievales existentes en el País Vasco en su vertiente cantábrica. Se trata de una construcción de dimensiones reducidas que debió gestarse en torno al siglo XI a tenor de los primeros datos históricos que nos hablan sobre Guipúzkoa. Esta fortificación, que aparece más cercana a los modelos de castillos roqueros altomedievales que a otros ejemplos más tardíos, no parece haber sufrido una transformación significativa con el paso del tiempo (Fig. 1). Aun así, las principales evidencias arqueológicas que se documentaron durante su excavación corresponden a las fases finales de la ocupación militar del recinto.

Las fuentes materiales, cuyas evidencias son claras en el territorio, constituyen un elemento fundamental para el conocimiento de un proceso histórico complejo, centrado en la articulación de un espacio de frontera, que se define más por una acción de vigilancia continuada y mantenimiento de un cierto statu quo, que por una actividad bélica sostenida en el tiempo (García, 2016: 399). La excavación de Mendikute permitió elaborar un registro arqueológico de calidad que dibuja las principales líneas de ocupación del asentamiento y que aporta valiosa información del mismo, a pesar de los procesos de reutilización y afectaciones posteriores. El conjunto de materiales recuperados a lo largo de las campañas de intervención representa una muestra singular de hallazgos arqueológicos fechados entre los siglos XIII y XIV. Entre los principales lotes de material se incluye un volumen ingente de restos faunísticos y una colección muy significativa de objetos de uso cotidiano en la fortaleza.

Entre ellos, se recuperó una colección muy representativa de elementos bélicos y restos del armamento empleado por una exigua guarnición de frontera entre los reinos de Castilla y Navarra. El repertorio bélico de Mendikute ha sido objeto de un análisis morfológico pormenorizado, a la luz de los paralelos existentes en la península y el continente europeo. Dicho análisis, realizado a partir de una documentación detallada de los materiales y una caracterización morfométrica exhaustiva, nos ha permitido definir los rasgos principales de estos elementos de guerra, que presentamos a lo largo de este trabajo.

\section{LA FORTALEZA DE MENDIKUTE Y EL HALLAZGO DE LOS MATERIALES}

El origen de la fortaleza de Mendikute (Albiztur, Guipúzcoa) parece remontarse al siglo XI. La primera constatación documental de la existencia de un territorio llamado Guipúzcoa se encuentra en un documento de 1025. En él se plasma la donación a favor del monasterio de San Juan de la Peña, del monasterio de San Salvador de Olazábal y otros bienes situados en Guipúzcoa por parte de García Acenáriz, senior de Ipuscua bajo el rey Sancho de Pamplona, y su esposa doña Galga (Ubieto, 1963). Esta donación recoge una referencia directa sobre el topónimo Albiztur e, indirecta, sobre la propia fortificación: «Sub nomine sancte Trinitatis. Ego quidem senior Garcia Açenariz et dona Gayla, pro remedio anime nostre, tradimus Deo donante illud monasteriom quod dicitur Ollazabal, cum hereditat seua, tu terminabit senior 

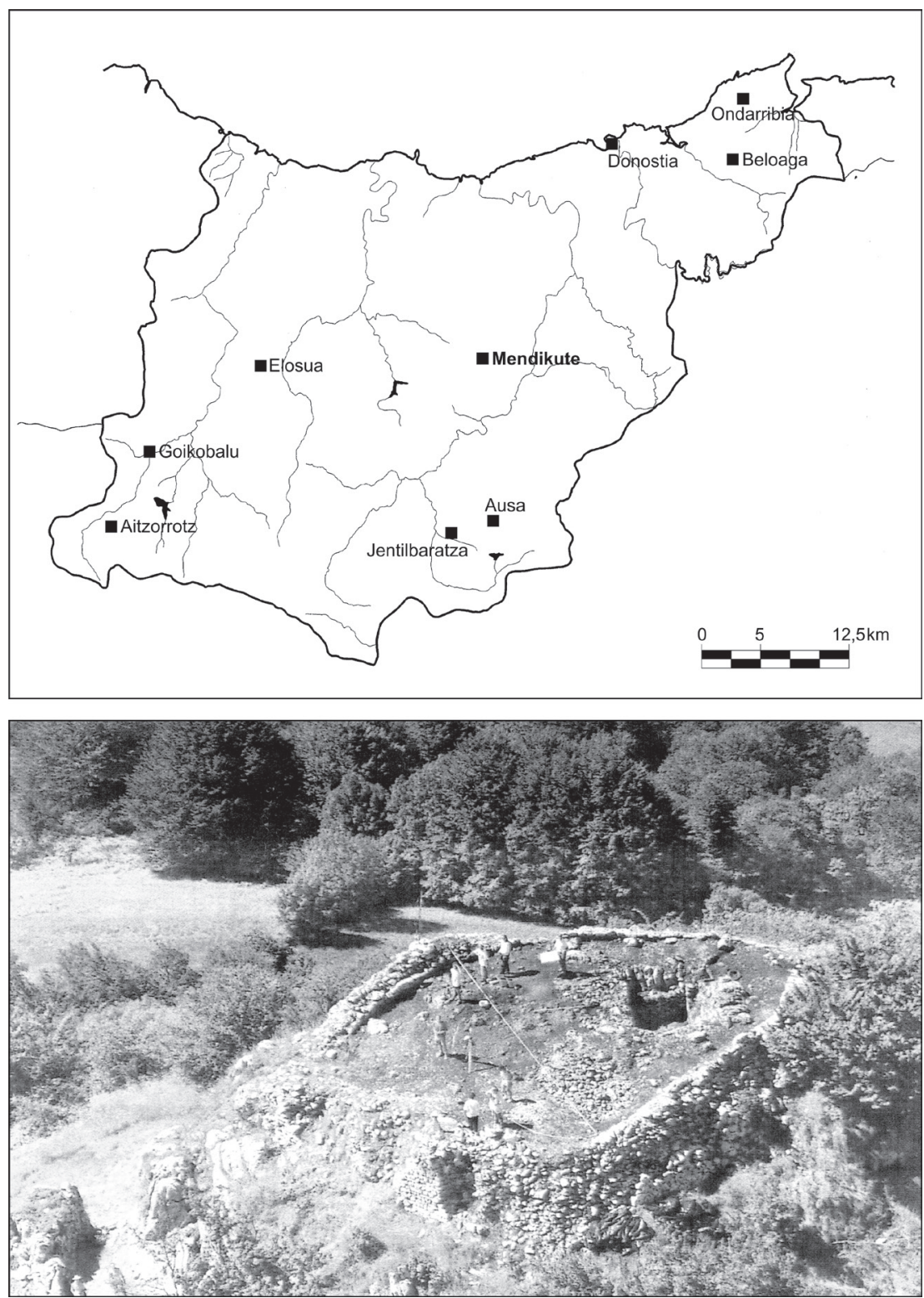

Figura 1. Mapa de localización de la fortaleza de Mendikute en relación con otras fortificaciones del País Vasco (arriba) y vista general del yacimiento (abajo). Mapa: J. I. Padilla; fotografía: GRAMP.UB.

Garcia Açenariz et dona Gayla des Scilice superiore, gaharraga Orer urte Alvitzt urre, super Lascurende».

El manzanar que entregan los donantes aparece situado bajo un topónimo compuesto típicamente latino, a pesar de las variables que ofrece la transcripción escrita. Se trata de una palabra compuesta que acoge el término albis y la expresión turris, de modo que su significado no es otro que el de torre blanca. Un examen del territorio, cuyo paisaje aparece dominado por los tonos verdes de la vegetación, nos permite advertir de inmediato que el único punto que podría corresponder con aquel calificativo sería la cumbre de Mendikute. La fortificación y su 
emplazamiento serían el origen del topónimo que ostenta el municipio, aunque el castillo acabará por adoptar otra denominación, también con una forma latina fosilizada (Mendi- [eusk. monte], -acatus [lat. agudo]) (Arocena, 1957: 313-315; Mitxelena, 1953: 92).

El documento de 1025 sería la prueba documental del origen de Mendikute en la primera mitad del siglo XI. Sin embargo, no hemos podido constatar arqueológicamente dicho hecho, debido a que los niveles más antiguos de la fortificación se encontraban fuertemente afectados por las acciones contemporáneas o bien por las profundas reformas que se realizan en el asentamiento a finales del siglo XIII. En cualquier caso, la excavación permitió recuperar una acuñación a nombre de Sancho IV de Navarra (1054-1076) que, a pesar de su contexto dudoso, atestigua la presencia antrópica en el yacimiento con anterioridad a las fases finales de ocupación documentadas en el registro arqueológico.

El territorio guipuzcoano, que en época medieval bascula entre el reino de Castilla y Navarra, acabará por integrarse en el reino castellano en tiempos de Alfonso VIII. El año 1200, según recogen la crónica de Jiménez de Rada y la Crónica Latina de los Reyes de Castilla, el rey castellano había obtenido «Victoriam. Ibida, Alavam et Guipuscoam [...] Alchorroza [...] terram que dicitur Ipuscaia, Sanctum Sebastianum insuper», recibiendo el dominio sobre el territorio con la entrega simbólica de varias fortificaciones guipuzcoanas vinculadas a las principales rutas de comunicación hacia el mar y, en algunos casos, dentro de las áreas de dominio de los denominados parientes mayores. Los castillos mencionados son los de «Sancum Sebastianum, Fortrm Rampitum, Beloagam, Aizcorreoz, Aussam, Athavit» (Barrena, 1989: 350). A partir de esta fecha, el territorio guipuzcoano aparece integrado dentro del reino de Castilla.

A pesar de que la fortaleza de Mendikute no aparece en aquella relación, no hay duda de su existencia en dicha época, ni tampoco de que aquella era administrada como una tenencia real. El propio escudo de la localidad de Albiztur, municipio donde se halla el yacimiento, avala la relación del territorio con la monarquía, pues recoge en su blasón las armas reales del reino de Castilla. La administración y control de esta fortificación debió de recaer en manos del poder local representado por los señores o parientes mayores. De esta forma, bajo la apariencia de legalidad real se esconde una muestra más del poder señorial. El dominio sobre los itinerarios que conducían hasta el mar y, especialmente de las rutas trashumantes y los espacios de pasto del entorno, son los que acabarán de dar pleno sentido a estas formaciones roqueras. Es aquí donde podemos encontrar plena justificación de la prolongada vigencia de su ocupación, incluso más allá del fortalecimiento de las villas reales que nacen en el territorio guipuzcoano.

El avance del poder real sobre el territorio guipuzcoano, cuya presencia se apoya en el nacimiento y desarrollo de las villas reales, alcanzará su máximo apogeo en el siglo XIII, anunciando un cambio sustancial en la estructura social y en la propia organización del territorio. Será en este contexto donde las viejas estructuras de tipo señorial entran en crisis, al igual que sus elementos más representativos, que son las fortificaciones. Es en este marco histórico donde se produce la deserción o abandono del espacio fortificado. Ello no quiere decir que los castillos desaparezcan por completo, sino que empieza a producirse una sustitución de las viejas formas de manifestación del poder señorial. Las torres o casas fuertes y palacios urbanos acabarán por dominar el paisaje urbano y rural.

Una de las aportaciones más interesantes de los trabajos arqueológicos ha sido poder constatar que, al menos en el caso de Mendikute y la fortaleza vecina de Ausa, estas estuvieron en uso al menos hasta las primeras décadas del XIV. En ambos emplazamientos se aprecia la realización de importantes obras de reparación durante la segunda mitad del XIII. Esta recuperación de las antiguas fortificaciones altomedievales no parece deberse a un conflicto coyuntural, sino más bien al intento de recuperar una parte de las antiguas rentas o percepciones señoriales. 
La fortificación de Mendikute está formada por dos ámbitos escalonados bien definidos y asentados sobre el suelo rocoso que definen un recinto superior o noble al que se accede desde un recinto inferior, probablemente destinado a caballerizas (Fig. 2). El recinto noble presenta una cisterna rectangular en la zona oeste y aparece delimitado por muros de mampostería a base de sillarejo aparejado en ambas caras. Esta estructura murada se utiliza también en el recinto inferior, donde el espacio además aparece flanqueado por baluartes. En el seno del recinto noble, se documentó la presencia de una cisterna y se determinaron tres sectores $(10,11$ y 12) para la gestión de la excavación que corresponden al ámbito occidental, central y oriental del recinto respectivamente, siendo el ámbito oriental el que concentra el mayor número de materiales, a pesar ser el más afectado por las reutilizaciones posteriores.

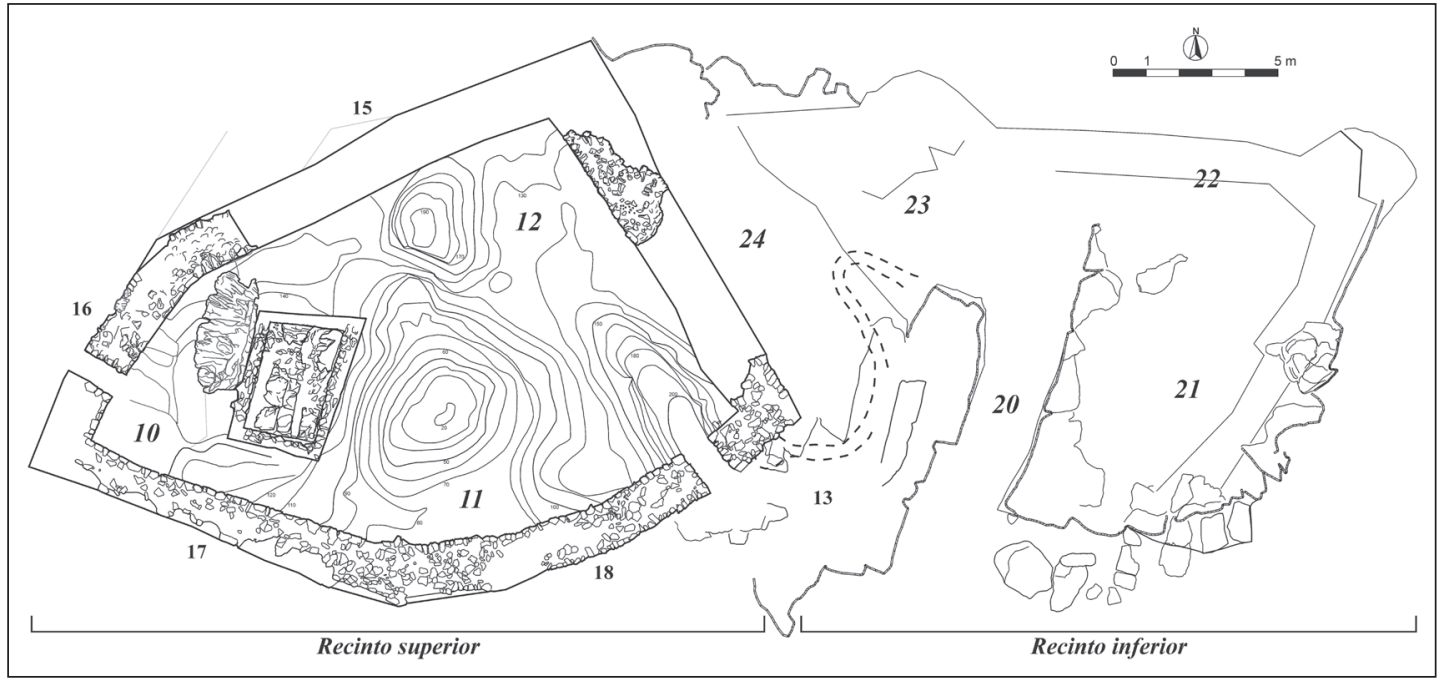

Figura 2. Planta general de la fortaleza de Mendikute. Autores: J. I. Padilla, K Álvaro, E. Travé.

Durante los trabajos de excavación, solo fue posible documentar una pequeña extensión de $1 \mathrm{~m}^{2}$ cuya secuencia estratigráfica no se hallaba alterada por acciones medievales y alteraciones contemporáneas y que registraba la fase más antigua documentada. Este nivel de utilización datado en el siglo XII, gracias a una acuñación de un dinero de Alfonso I de Aragón, representa el único testimonio que ha sobrevivido de las etapas iniciales de la fortificación. En el resto del yacimiento no ha sido posible registrar estos niveles, debido a las alteraciones modernas y a las profundas reformas que sufre el recinto a finales del siglo XIII. De esta manera, el depósito arqueológico de las restantes áreas del emplazamiento, solo documentan la última etapa de utilización de la guarnición, que debe fecharse entre la segunda mitad del XIII y primeras décadas del siguiente.

Las grandes obras de reconstrucción de la fortificación de mediados del siglo XIII eliminan toda posibilidad de encontrar la secuencia antigua dentro de la mayor parte del recinto noble. La última fase medieval del yacimiento aparece documentada, esencialmente, en el recinto inferior. Los trabajos sobre este ámbito nos inducen a pensar que existió una construcción rústica, de planta rectangular, que se levantaba sobre los antiguos muros. La secuencia estratigráfica parece insinuar que debió de haber una ocupación temporal, acaso relacionada con el pastoreo. Su cronología debe situarse, obviamente, con posterioridad a la deserción de la fortificación, quizás en torno al siglo XV. Aunque no existen elementos de datación 
segura que corroboren esta afirmación, algunos indicios como la presencia de una acuñación portuguesa de mediados del siglo XV aparecida en el recinto noble parecen sugerir que dicho espacio habría sido utilizado para guardar ganado a finales de la Edad Media.

La primera acción contemporánea sobre el yacimiento se documenta en 1911, con una intervención de I. Mendizábal y E. Retondo, que afecta a varias áreas del emplazamiento. Al iniciar los trabajos se pensaba que su intervención solo afectaba a la excavación de la cisterna o aljibe que preside el recinto noble, pero se ha probado en los trabajos de excavación la existencia de diversas alteraciones sobre el depósito arqueológico que han dificultado sustancialmente las labores de excavación. Por otro, lado, la excavación arqueológica puso de manifiesto la existencia de otra fase de alteraciones de la estratigrafía durante la ocupación militar del recinto a principios de la Guerra Civil Española. Esta fase aparece perfectamente identificada a partir de varias trincheras y pozos de tirador, así como de los materiales recogidos durante los trabajos de excavación correspondientes a este periodo, entre los que se cuentan munición de arma corta, de fusil y varios cargadores.

Ambas acciones relacionadas con estas fases de afectación contemporánea junto con otras actividades clandestinas también actuales, han mermado sustancialmente el depósito arqueológico del yacimiento, por lo que resultó imprescindible durante la excavación documentar detalladamente todas las alteraciones desde su fase inicial a fin de poder interpretar con seguridad el registro arqueológico de las fases antiguas.

El conjunto de materiales recuperados constituye un valioso testimonio para el conocimiento de la vida en estas guarniciones de frontera, que controlaban un espacio fronterizo entre los reinos de Navarra y Castilla. Junto al monetario destaca la serie de objetos correspondientes al armamento militar, que son objeto principal de nuestro trabajo, así como una amplia muestra de apliques metálicos (Álvaro y Travé, 2019). El mobiliario óseo ofrece, además, aportaciones muy interesantes porque permitió constatar la existencia de una práctica habitual de reutilización de los restos faunísticos, no solo para la elaboración de útiles funcionales sino también para la fabricación de dados y fichas de juego en el seno de la fortificación (Álvaro et alii, 2017).

\section{EL MÉTODO DE ANÁLISIS MORFOMÉTRICO}

Los materiales bélicos de la fortaleza de Mendikute están formados por un nutrido grupo de puntas de flecha y lanza, junto con algunas armas de empuñadura como las dagas o cuchillos. Junto a ellos, se han detectado también algunos otros elementos de carácter auxiliar como los ganchos de armar la ballesta. Todas estas piezas constituyen un buen elemento para profundizar en el conocimiento de los útiles bélicos y su significado arqueológico y su estudio puede proporcionar un buen paralelo para otros yacimientos coetáneos. Para ello, es necesario definir una seriación precisa con base en criterios cuantitativos con el fin de posibilitar la explotación estadística de los datos. Ello nos proporciona una clasificación precisa, con base en las dimensiones de las distintas partes que componen el arma, que parte de un proceso de objetivación de las variables de estudio.

Por ello hemos considerado una serie de variables calculadas a partir de un dibujo bidimensional y a escala real de cada fragmento que incluyen la longitud total de la pieza $(h)$ expresada en milímetros, así como la longitud total de la punta $(p)$ y del enmangue (e), de las partes anterior y posterior de la punta $\left(p_{a^{\prime}} p_{p}\right)$ en relación con la anchura máxima $\left(a_{\max }\right)$, la anchura de la parte anterior de la punta en su punto medio $\left(a_{1 / 2}\right)$ y en la base de la punta $(a)$ así como el diámetro del enmangue $\left(d_{e}\right)$. En el caso de las saetas, se ha considerado además 
la longitud del vástago (v) y la suma de longitudes del vástago y el enmangue $(v)$. A estos parámetros, sobradamente conocidos (Orton, 1988; Barker, 1975), hemos añadido una variable $(r)$ de carácter vectorial que considera la relación existente entre el extremo de la punta, el del enmangue y la anchura máxima en relación con un vértice inmóvil con coordenadas $(0,45 h ; 0,5 h)$ respecto del extremo inferior izquierdo de la pieza (Fig. 3). En el caso de las dagas o cuchillos se ha considerado la longitud total $(h)$ o, en su defecto, la conservada $(h)$, la anchura de la hoja en el enmangue $\left(a_{e}\right)$, su anchura máxima $\left(a_{\text {máx }}\right)$, y el grosor de la misma en el filo $(g)$ y en el contrafilo $\left(g_{c}\right)$.

Este análisis específico nos ha permitido precisar los rasgos de una seriación propuesta a partir de la explotación estadística de las distintas variables morfométricas observadas (Fig. 4) a partir del análisis de componentes principales y de la comparativa de variables dos a dos, cálculos que ya se han revelado exitosos como determinantes tipológicos en estudios previos (Ledesma, 2003). En el caso de los proyectiles, las diferencias en las proporciones entre la anchura y longitud de la punta singulariza las características principales de las lanzas, mientras que en el caso de las flechas, su morfología es mucho más homogénea, con unos tipos que se distinguen fundamentalmente en función del tamaño (Fig. 4a). En este segundo caso, la proporción entre la longitud total y la longitud de la punta constituye uno de los elementos definitorios de los tipos de flecha identificados a pesar de la correlación elevada de ambos parámetros (Fig. $4 b)$. Variables con una correlación menor como la longitud total de la punta en relación con la longitud de la parte anterior de la misma (fig. 4c) o bien entre la punta y el enmangue (Fig. 4d) permiten precisar los rasgos característicos de tipos tanto de flecha como de lanza. En el caso de las lanzas, estas variables

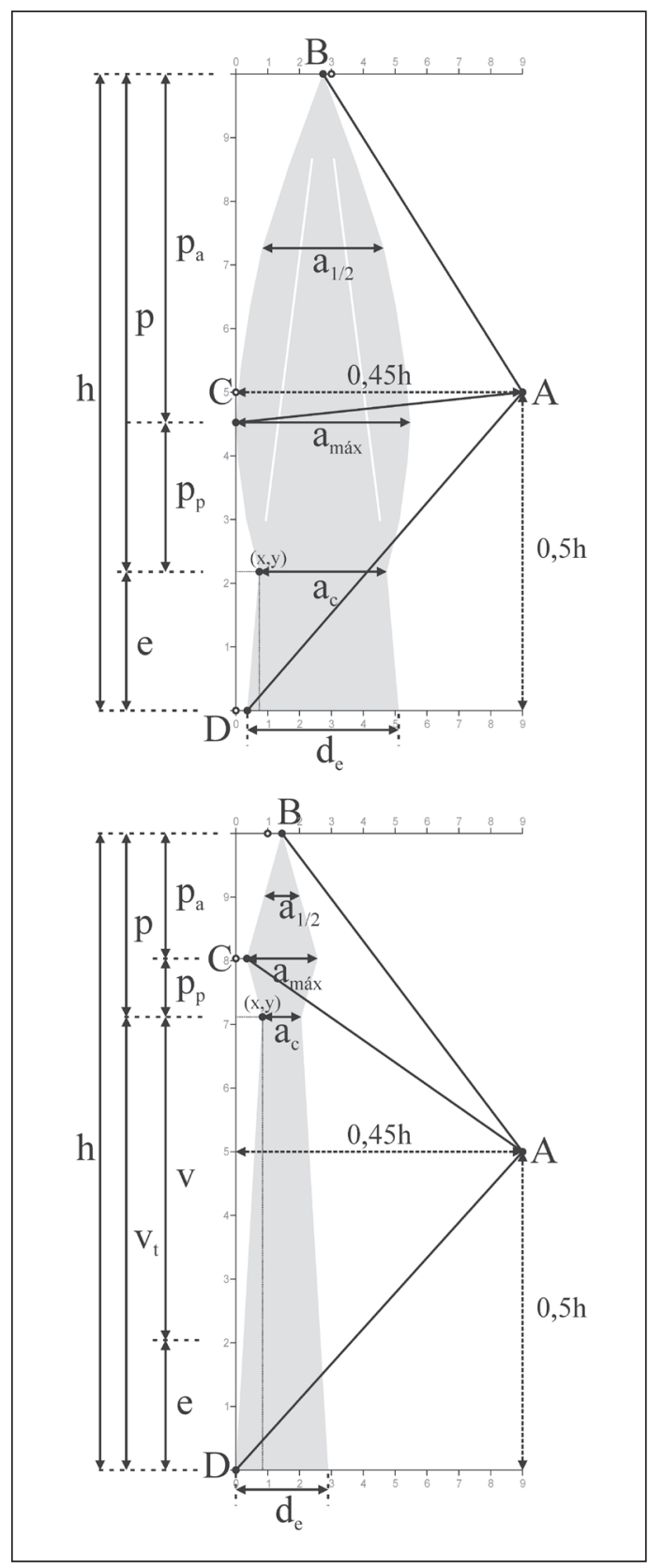

Figura 3. Variables morfométricas calculadas para el estudio tipológico de los proyectiles de Mendikute: lanzas (superior) y puntas de flecha o ballesta (inferior). Dibujo: E. Travé. también permiten definir variantes para tipos con una morfología similar. Definimos a continuación los principales resultados obtenidos del estudio, estructurados con base en los tipos identificados para el conjunto de flechas, lanzas y cuchillos. La mayoría de ellos cuentan con numerosos paralelos que nos permiten discutir la representatividad, trascendencia y significación histórica de los tipos identificados. 


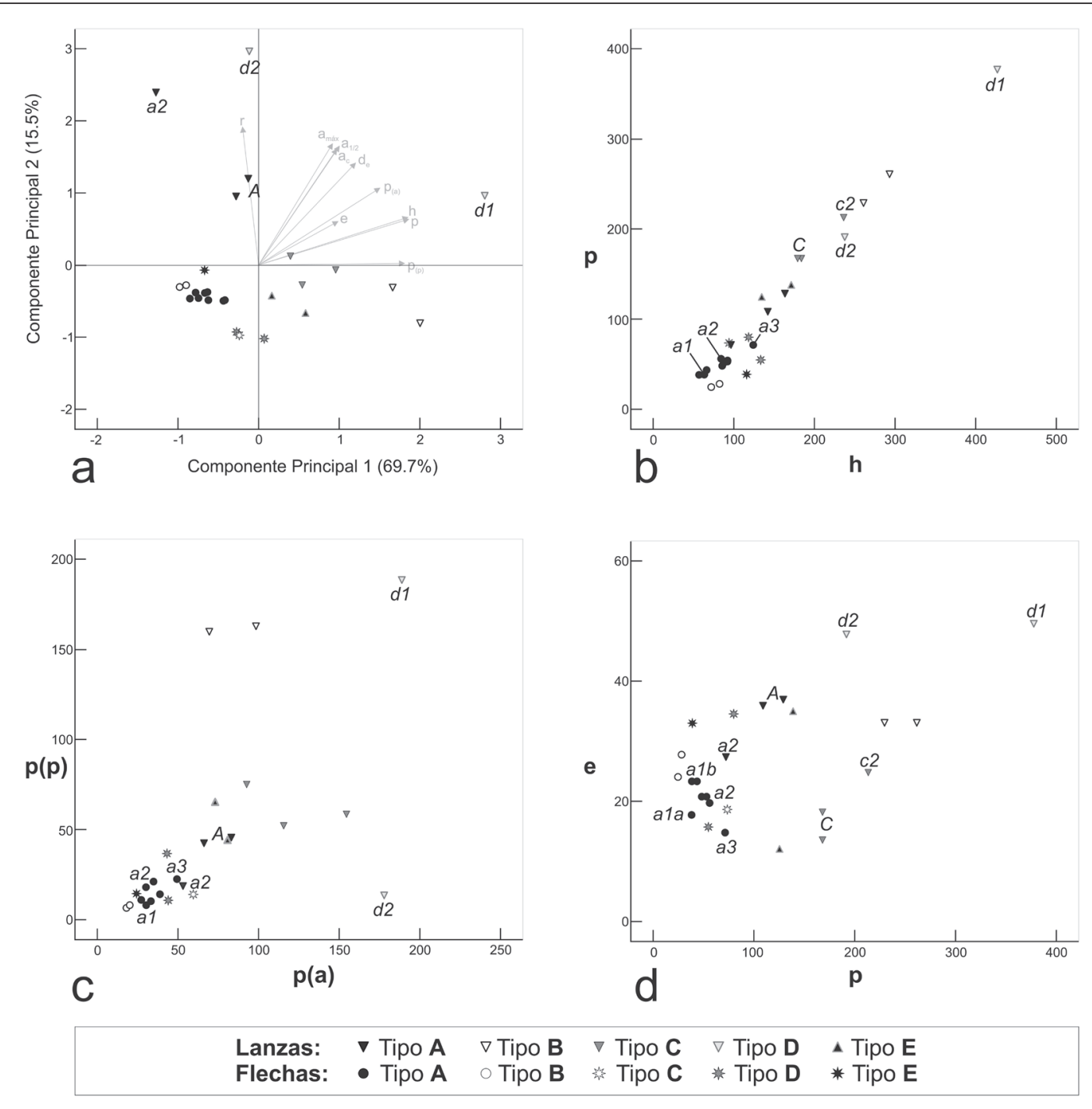

Figura 4. Gráficos de doble variante resultantes del análisis de componentes principales (ACP) para el conjunto de proyectiles (a) y comparativos de distintas variables dos a dos (b-d). Gráficos y composición de la figura: E. Travé.

\section{RESULTADOS: EL MATERIAL BÉLICO DE MENDIKUTE}

Entre el conjunto de armamento recuperado en la fortaleza, se cuentan puntas de flecha o ballesta - la adscripción a una función u otra la determinamos, como veremos, en función de su morfología y clasificación - lanzas y dagas y cuchillos, junto con algunos elementos auxiliares también de carácter bélico, como los ganchos para armar la ballesta. Los resultados del análisis morfométrico realizado nos permiten sintetizar a continuación las características siguientes para cada grupo de materiales. 


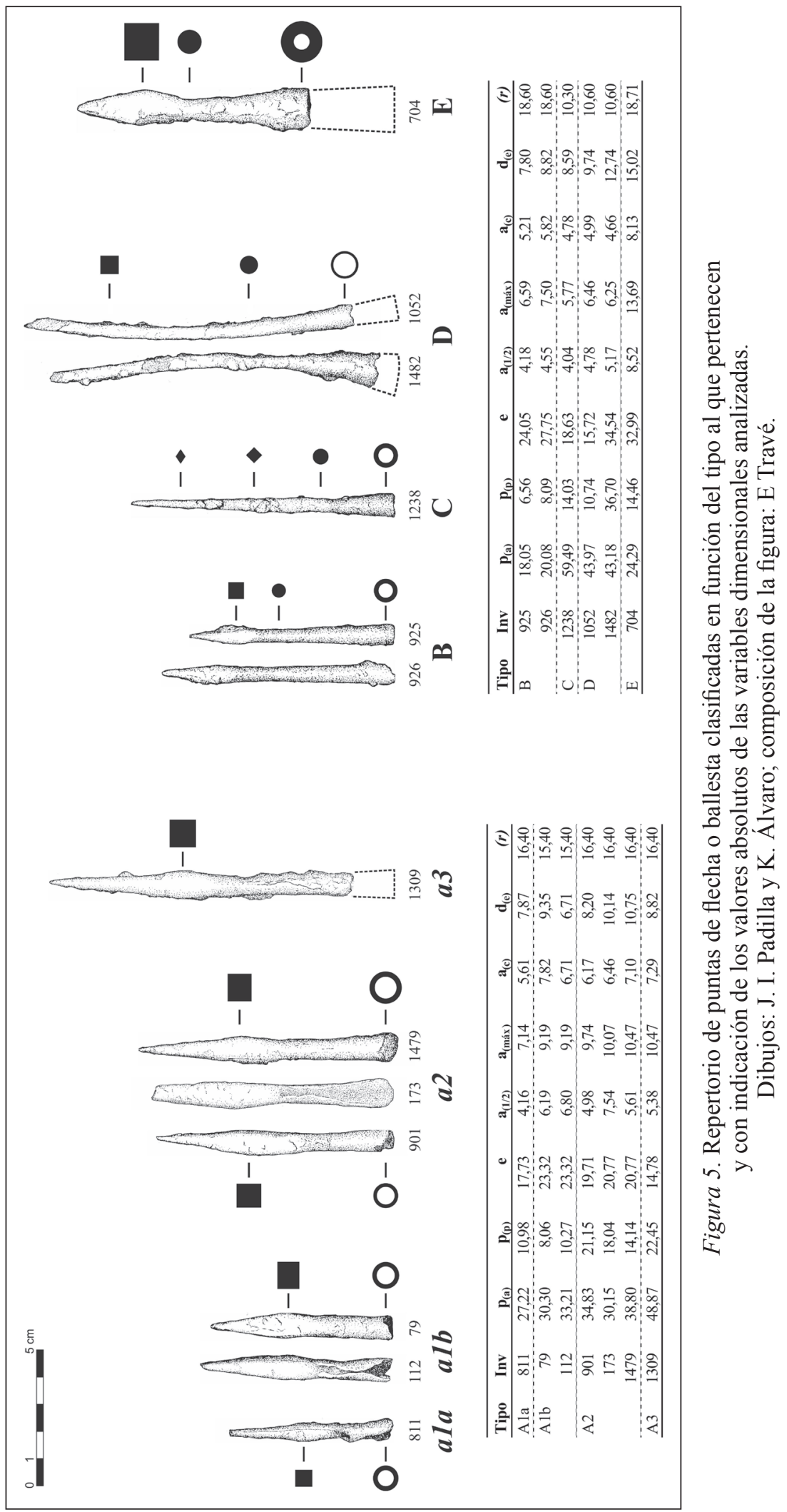

Gladius, XL (2020), pp. 133-152. ISSN: 0436-029X; eISSN: 1988-4168. https://doi.org/10.3989/gladius.2020.06 


\subsection{Proyectiles para flecha o ballesta}

El conjunto de saetas o dardos recuperado en Mendikute constituye el elemento más representado de todo el repertorio bélico identificado. En total se documentan 166 piezas que presentan un estado de conservación dispar. Entre ellos, las variantes detectadas responden principalmente a las dimensiones variables de los distintos ejemplares que presentan una misma morfología (Fig. 5):

Tipo A - Corresponde a una punta de saeta de traza romboidal, compuesta por una punta piramidal de sección cuadrada y enmangue tubular con ligero estrangulamiento en su unión. Los ejemplares se presentan bajo tres variantes en función de sus dimensiones entre $6-12 \mathrm{~cm}$ de longitud. La variante de menores dimensiones (a1) incluye ejemplares con una longitud entre $6-7 \mathrm{~cm}$, con un diámetro de enmangue alrededor de los $8 \mathrm{~mm}$. Las puntas de flecha que constituyen la variante predominante (a2) presentan medidas comprendidas entre los 8,5 - 9,5 $\mathrm{cm}$ de longitud, con un diámetro de enmangue alrededor de los $10 \mathrm{~mm}$. Finalmente, la variante de mayores dimensiones a 3 es poco habitual y supera los $12 \mathrm{~cm}$, con un enmangue algo superior a los $10 \mathrm{~mm}$ de diámetro.

Tipo $B$ - Las puntas de saeta de este tipo se componen de una cabeza piramidal cuadrada de pequeñas dimensiones y cuerpo de sección circular y enmangue tubular ligeramente cónico, que se desarrolla desde aquel. Se han recogido muy pocos ejemplares de este tipo estilizado, en el que predomina el aspecto cónico. Con una longitud total entre 7,5-9 cm y un enmangue de $7-8 \mathrm{~mm}$ de diámetro, destaca la proporción aproximadamente de un cuarto a tres cuartos entre la punta o cabeza y el vástago respectivamente.

Tipo $C$ - Estas puntas de saeta son de traza piramidal, con una cabeza prolongada de sección romboidal a lonsángica, con ligero estrechamiento del cuerpo de sección circular y enmangue de tipo cónico. Presentan una longitud total de unos $10 \mathrm{~cm}$ y un enmangue de $8 \mathrm{~mm}$ de diámetro. En este caso destaca también la proporción entre la punta y el vástago, que, en oposición con el grupo anterior, es de dos tercios a uno también respectivamente.

Tipo $D$ - Los ejemplares incluidos en este tipo corresponden a saetas de gran desarrollo, largas, delgadas y puntiagudas. Oscilan alrededor de $10 \mathrm{c} 15 \mathrm{~cm}$ de longitud y se componen de una punta piramidal larga - la mitad de la longitud total o más en la mayoría de casos - de sección cuadrada y con ligero estrechamiento sobre el cuerpo y también de enmangue tubular cónico. El vástago es de sección circular y el enmangue, proporcionalmente más corto que en otros tipos, presenta un diámetro superior a los $10 \mathrm{~mm}$.

Tipo E - Este tipo presenta grandes dimensiones y lo componen una cabeza romboidal engrosada y un cuerpo de sección circular con enmangue tubular de tipo cónico. Se ha recuperado un solo ejemplar en todo el conjunto, cuyo peso y dimensiones indican que se trata de una vira para ballesta. Sus dimensiones difieren notablemente de los tipos anteriores (Fig. 4a), especialmente en la relación entre la anchura — de $12 \mathrm{~mm}$ en su punto máximo y, por tanto, claramente superior al resto- y la morfología del vástago y enmangue, con una cabeza de pequeñas dimensiones en proporción.

\subsection{LAS PUNTAS DE LANZA}

La mayor parte de los ejemplares recuperados en Mendikute son piezas de grandes proporciones que presentan enmangue tubular para su inserción en el asta. Algunos de los tipos que analizaremos a continuación son de sección maciza, pero existen también otras formas huecas 
con pronunciados nervios axiales que revelan un procedimiento tecnológico de elaboración muy preciso.

El análisis morfológico de los materiales nos permite proponer una clasificación en función de cinco tipos claramente individualizables, con algunas variantes menores para algunos de ellos. La distinción entre tipos responde fundamentalmente a la forma de la hoja, mientras que la identificación de variantes viene dada habitualmente por la detección de rangos de dimensión distintos o por leves variaciones morfológicas en el filo de la hoja. Así, identificamos (a) puntas de hoja sencilla, lanceolada, de dimensiones reducidas, (b) lanzas de hoja larga y estrecha, (c) puntas de hoja de sauce, (d) formas triangulares y (e) piramidales sencillas (Fig. 6).

Tipo $A$ - Este tipo de lanzas presentan hojas lanceoladas sencillas que se definen por su forma plana, triangular y con filos curvos en la base. Presentan nervios axiales de sección romboidal hueca y un enmangue tubular ligeramente cónico, puesto que se presenta como una prolongación de los nervios axiales. Entre las lanzas que se incluyen en este tipo, generalmente de unos $16 \mathrm{~cm}$ de longitud, destacan algunas de dimensiones algo más reducidas (c. $12 \mathrm{~cm}$ de longitud) con alas algo menores que constituyen una variante (a2) del mismo. La distinción de

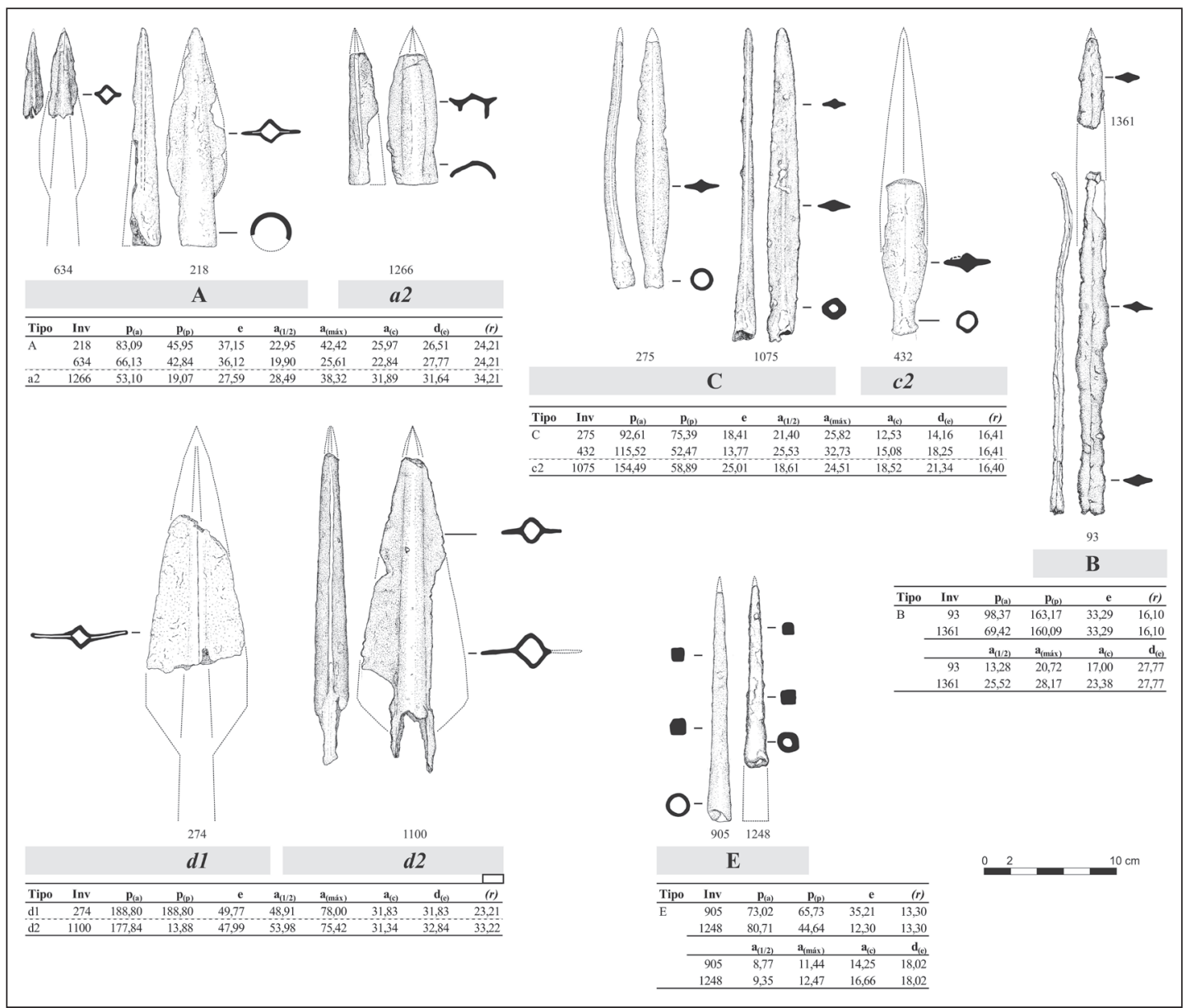

Figura 6. Repertorio de puntas de lanza clasificadas en función del tipo al que pertenecen y con indicación de los valores absolutos de las variables dimensionales analizadas. Dibujos: J. I. Padilla y K. Álvaro; composición de la figura: E Travé. 
ambas variantes es clara, tanto a partir del análisis de componentes principales (Fig. 4a) como de la comparación entre variables, especialmente en los valores relativos a la proporción entre la punta y el enmangue o la parte anterior y posterior de la punta.

Tipo $B$ - Definimos este tipo a partir de la forma larga y estrecha de su hoja, de gran desarrollo y enmangue bastante más bajo en comparación con los restantes tipos. Presenta sección maciza y romboidal, con aristas axiales, y una longitud máxima de $25-30 \mathrm{~cm}$. El enmangue es tubular o cilíndrico y podría abarcar una tercera parte de la longitud total de la pieza, aunque los ejemplares de que disponemos se conservan todos ellos de manera fragmentada.

Tipo $C$ - Responde a la denominada hoja de sauce, de sección maciza y romboidal, también como en el caso anterior, con aristas axiales. De longitud mucho menor que el tipo anterior - no suele superar los $20 \mathrm{~cm}$ - presenta un enmangue tubular del cual no conocemos con fiabilidad su desarrollo. Este tipo presenta una variante (c2) que presenta variaciones leves en las dimensiones — es algo más larga - pero no en la forma.

Tipo $D$ - Corresponde a una hoja de grandes dimensiones, muy característica, de forma triangular y quizás terminada con filo recto. Aparece dotada de pronunciados nervios axiales de sección romboidal y hueca. Presenta un enmangue tubular, aunque entre las piezas que conservamos no se ha recuperado ningún ejemplar completo (d1). Entre los ejemplares fragmentados de que disponemos, existen algunas divergencias que permiten definir una variante de características similares (d2), aunque con nervios axiales más angulosos y menos pronunciados.

Tipo $E$ - El último tipo documentado pertenece a una punta piramidal simple, a modo de punzón, maciza y de sección cuadrangular. El enmangue tubular responde al desarrollo formal lógico de la punta y equivale en longitud a una cuarta parte de las dimensiones totales de la pieza, que alcanza los $17 \mathrm{~cm}$ de longitud.

\subsection{LAS DAGAS Y CUCHILLOS}

Estos elementos aparecen en el recinto superior, preferentemente concentrados en el sector 12, pero también en el exterior del recinto (sector 15), entre los niveles de derrumbe del muro perimetral. Excepcionalmente, hallamos algún ejemplar en los sectores 10 y 11 (las piezas 240 y 524 son las más representativas de esta zona). El conjunto se compone en su mayoría de cuchillos, de grandes proporciones, cuyas hojas de un solo filo superan los $30 \mathrm{~cm}$ de longitud, con vástago para su encaje en el enmangue. En general, suelen presentar en ambas caras un canal axial, que debe ocupar, al menos, la mitad de la hoja. Las dos piezas mejor conservadas muestran las variaciones posibles dentro de este objeto. La pieza 92 (Fig. 7, tipo A), por ejemplo, presenta una hoja más esbelta, de $29 \mathrm{~cm}$ de longitud por $2 \mathrm{~cm}$ de anchura, frente al ejemplar 829 (tipo B), que posee un desarrollo rectilíneo y una longitud de hoja de $31,8 \mathrm{~cm}$ de longitud por 2,6 cm de anchura.

Junto a las piezas anteriores hemos agrupado también otros ejemplares de cuchillos. Estos objetos, que en todo caso son fragmentarios, muestran los tipos habituales de uso en la fortificación. El cuchillo 1125 (tipo C), presenta una hoja corta, delgada y con un filo arqueado que a juzgar por su morfología no parece demasiado más largo que la parte conservada. El resto de ejemplares presentan dimensiones menores y formas diversas, debido en parte a su estado fragmentario. En algunos casos, las variables analizables son escasas y dificultan la asignación a tipos concretos con un grado suficiente de fiabilidad (b/c). El fragmento 524, podría corresponder al tipo de cuchillo de mayores proporciones aunque de factura parecida a las grandes dagas, aunque de hoja más estrecha, de 13,1 cm de longitud por 5,5 $\mathrm{cm}$ de anchura. Al contrario de lo que es habitual, en este caso se conserva el enmangue de sección rectangular. 


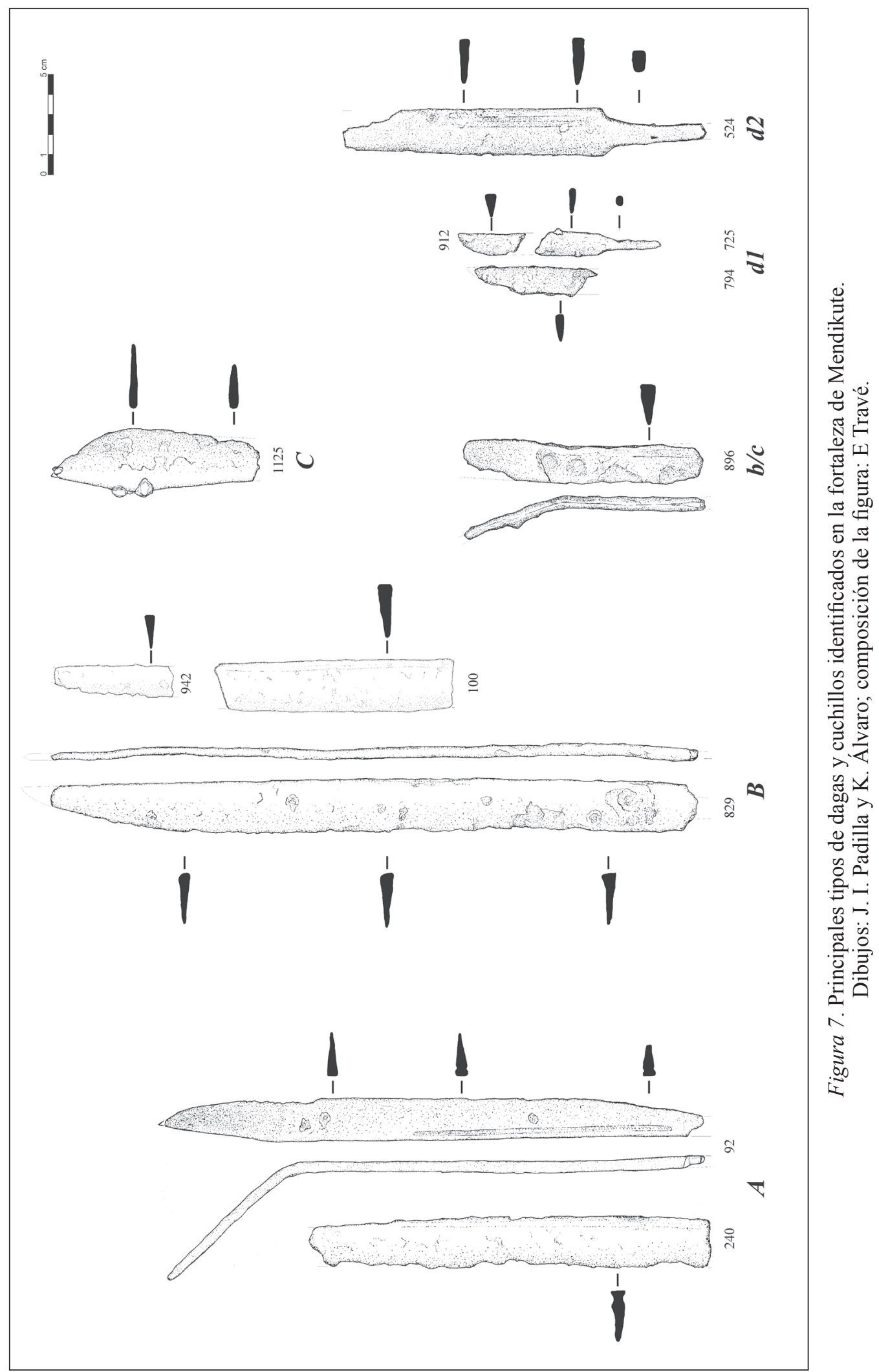

Gladius, XL (2020), pp. 133-152. ISSN: 0436-029X; eISSN: 1988-4168. https://doi.org/10.3989/gladius.2020.06 


\subsection{OTROS ELEMENTOS AUXILIARES}

La muestra de armamento recoge además dos ganchos (1237 y 164) (Álvaro y Travé, 2019) relacionados con el equipamiento de la ballesta. El ejemplar 1237 fue recuperado sobre uno de los pavimentos de la etapa final de ocupación militar del recinto, en las proximidades del hogar 12.224 y dentro del área de cocina. Por el contrario, la pieza 164 proviene de uno de los depósitos contemporáneos, generado por las actividades realizadas en el pasado siglo, que alteraron sustancialmente una parte del depósito antiguo. En cualquier caso, ambos ejemplares presentan una traza y periodización similar y deben fecharse entre mediados del siglo XIII y las primeras décadas del XIV.

Las piezas, que aparecen perfectamente adaptadas a la fuerza de tracción que debe ejercerse en el proceso de armado de la ballesta, presentan una estructura similar, aunque con algunas diferencias formales. Ambas se componen de un sólido gancho de sección circular, cuyo extremo aparece reforzado y bien forjado a fin de resistir la tensión de la cuerda. El cuerpo se divide en dos ramas a fin de constituir una cavidad central suficiente donde alojar la correa de sujeción del instrumento, que finaliza sobre un apéndice plano, más o menos prolongado y ancho según el caso. El ejemplar 1237 presenta un aspecto esbelto y de mayores proporciones que la segunda pieza, aunque esta última ofrece en contrapartida una mayor solidez. Tanto la región anular o la central, como el apéndice, ofrecen variaciones de elaboración en cada una de las piezas mencionadas.

\section{DISCUSIÓN: CRONOLOGÍA Y PARALELOS}

El repertorio de elementos presentado cuenta con numerosos paralelos en la Península Ibérica y el territorio de la Europa Meridional (Serdon, 2005) y sus variaciones morfológicas examinadas a la luz de los paralelos existentes, aportan valiosa información de carácter cronológico y territorial. En lo referente a las puntas de flecha o saeta, la variedad de tamaños que constituyen variantes identificadas dentro de los tipos establecidos no parece responder a una variación tipológica significativa sino que deberían explicarse con base en la elaboración rápida de este tipo de útiles dentro de una cadena de producción en masa realizada ante cualquier conflicto bélico (Rénoux et alii, 2009).

Uno de los problemas que presentan las saetas o dardos radica en saber si deben vincularse al uso del arco o de la ballesta. Es decir, si existen diferencias sustanciales entre los proyectiles que lanzan una u otra arma en una época anterior al siglo XIV. Desde un punto de vista funcional, la mayoría de formas recuperadas en Mendikute se podrían considerar como puntas de flecha, aunque el ensanchamiento central de la punta piramidal, que refuerza el aspecto romboidal de la pieza en el tipo E, sugiere en este caso su posible utilización como proyectil para ballesta (Fig. 8). Sea como fuere, cabe advertir que la verdadera difusión de la ballesta en la península se produjo durante el siglo XII, por lo que debemos suponer que las primeras saetas para esta nueva arma no se debían diferenciar en gran manera de los modelos utilizados para el arco, si es que no se utilizaban indistintamente.

Este tipo de punta, que acaso tuvo una función polivalente, debió de alcanzar una notable difusión, perdurando al parecer al menos hasta el siglo XIV. Sería entonces, cuando las modificaciones introducidas en la ballesta, que la dotan de mayor potencia de tiro, permitiría la adopción de nuevas puntas de flecha más consistentes y con mayor poder de penetración.

Existen numerosos paralelos datados, por lo general, dentro del siglo XIII o primera mitad del XIV para las saetas que hemos determinado como tipo $A$, lo que indica su amplia difusión 


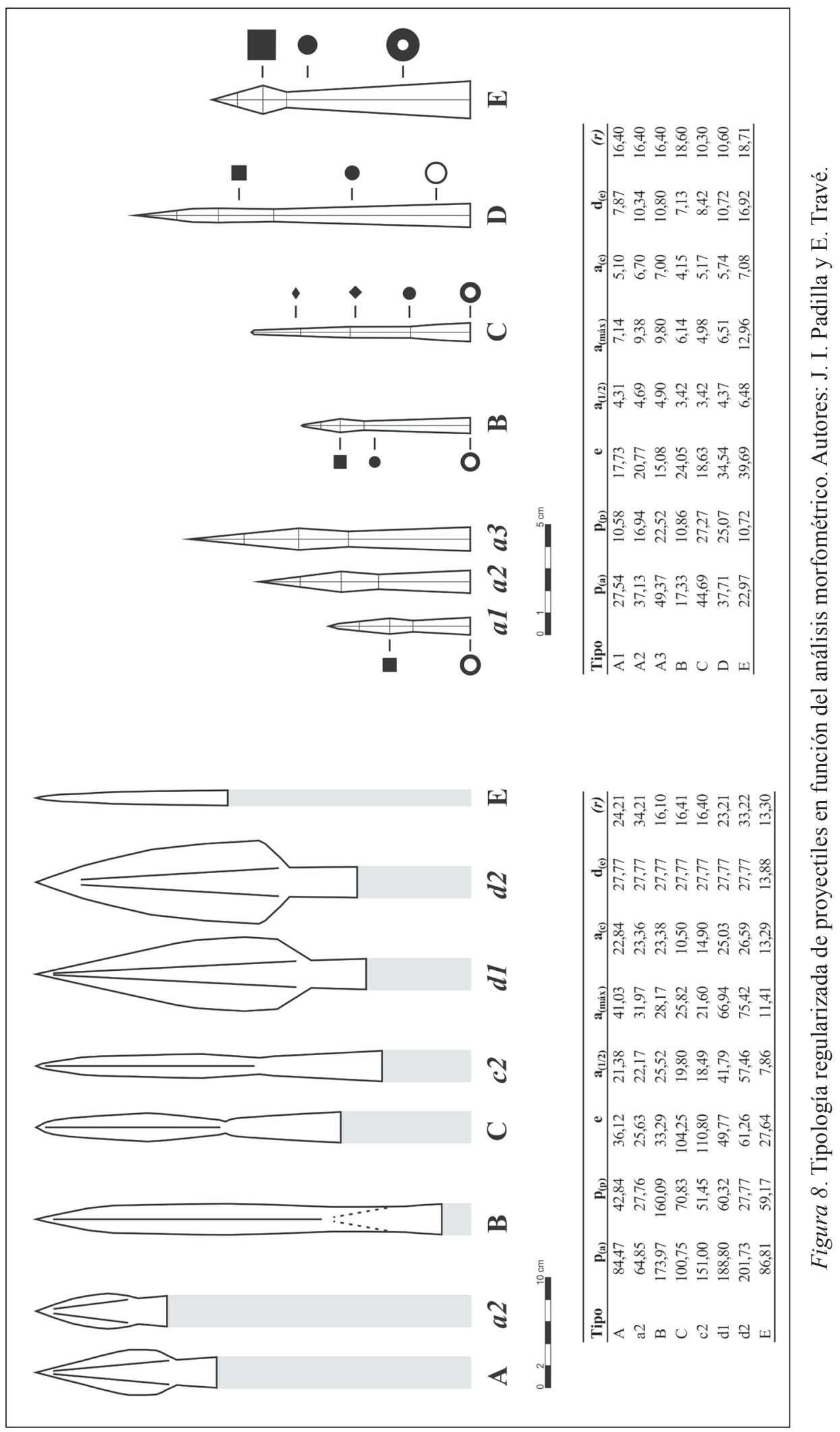

Gladius, XL (2020), pp. 133-152. ISSN: 0436-029X; eISSN: 1988-4168. https://doi.org/10.3989/gladius.2020.06 
espacial y cronológica. Este tipo es conocido en la península al menos desde los siglos $\mathrm{X}-$ XI, como atestigua su aparición en las ciudades musulmanas de Vascos (Toledo) y Calatalifa (Madrid). Su presencia es predominante no solo entre el armamento almohade de los contextos de las batallas de Alarcos y de las Navas de Tolosa (1195 y 1212), sino también en diversos asentamientos castrales cristianos (Zozaya, 1995: 175).

Dos ejemplares similares a este tipo fueron recuperados en las excavaciones del vecino castillo de Aitzorrotz (Escoriaza, Guipúzcoa) y están datados entre finales del XIII y primera mitad del XIV (Barandiarán, 1970). Aparecen también entre los tipos de saeta del castillo de Montségur (L'Ariège) y, aunque el número de ejemplares sea reducido en este caso, existen numerosos paralelos en la región que se fechan dentro del siglo XIII (GRAME, 1980: 117118). Asimismo, aparece como una de las formas más usuales entre el armamento provenzal del siglo XIII y se documenta en la villa fortificada de Rougiers (Var), en contextos de idéntica cronología.

El tipo B de Mendikute, por el contrario, parece ser una forma menos usual, aunque su aspecto es similar a muchas piezas que presentan una cabeza prismática de sección triangular. Esta variante triangular está mucho más extendida y aparece con frecuencia en contextos del siglo XIV en Rougiers (Var) o en Montségur (L'Ariège) (GRAME, 1980: 118-120). También la encontramos en contextos mucho más antiguos como es el caso del ejemplar localizado en el Castillo de Mértola y datado del siglo XI (Barroca y Gouveia, 2000: 96, 368).

Dado que únicamente se ha identificado un ejemplar de tipo $\mathrm{C}$ en la excavación, desconocemos si este constituyó un modelo habitual del yacimiento. En cualquier caso, la forma parece en general bastante más extraña, puesto que no hemos hallado paralelos o referencias directas a la misma en otros conjuntos consultados. El tipo D también aparece representado por un número muy escaso de individuos, la mayoría de ellos fragmentados. Sin embargo, las excavaciones del castillo de Montségur (L'Ariège) proporcionan un tipo de saeta piramidal muy próximo al tipo D de Mendikute. Es aquel caso, los ejemplares de estas características predominan indiscutiblemente sobre una muestra de 250 piezas clasificadas en 12 tipos formalmente diversos. Dichas piezas, que presentan una longitud entre 100-200 mm parecen ser un tipo habitual en este ámbito pirenaico, ya que se documentan paralelos tanto en la región de Aude como en el Tarn, siempre en contextos que datan del pleno siglo XIII (GRAME, 1980: 115-118). Estos tipos aparecen también tanto en yacimientos almohades, como Calatrava la Vieja o Alarcos (Zozaya, 1995: 476), como en castillos cristianos plenomedievales, como en Camargo (Santander) o Barrios de Luna (León) (Zozaya, 1995: 176, núm. 4).

Existen algunos ejemplares de vira para ballesta de proporciones similares al tipo E de Mendikute entre las puntas recuperadas en Puente Castro (León), también con cabeza engrosada, de sección cuadrada, a las que se les atribuye una cronología posterior al siglo XII (González, 2007: 84; 2013, 132-133). Existen otros paralelos entre las 11 puntas de vira exhumadas en las excavaciones del castillo de Aquiar da Pena (Pontido, Vila Pouca de Aguiar, Portugal) recuperadas en contextos datados, con algunas dudas, del siglo XIV. Sin embargo, a diferencia de la pieza que presentamos, todos aquellos ejemplares presentan cabeza prismática de sección triangular (Barroca y Gouveia, 2000: 402-405, núm. 150-157), forma que parece predominante entre las piezas peninsulares de los siglos XIV y XV. En cualquier caso, la punta de sección cuadrada no es extraña tampoco en los contextos del Bierzo vinculados a las revueltas irmandiñas, como los del castillo de Cornatel o en la Torre Mayor del castillo de Corullón (González, 2012: 132, 134).

El conjunto de lanzas de Mendikute, parece ser en su mayoría coetáneo. Así lo indica la disposición estratigráfica de estas piezas, ya que varios de los tipos identificados conviven en el seno de un mismo contexto estratigráfico. Así, por ejemplo, el depósito 10.116, que 
corresponde a los niveles de utilización de un pavimento de finales del XIII o principios del XIV, ofrece tres tipos diferentes (A, C y d1) de punta de lanza (Fig. 8). Del mismo modo, un contexto ligado a la última fase del área de cocina de la guarnición (UE 12.210), datada en la primera mitad del XIV, aparecen dos nuevos tipos (a2 y E) distintos de los anteriores. En definitiva, podemos afirmar que todos los elementos de la clasificación propuesta estaban en uso en este periodo comprendido entre la segunda mitad del XIII y la primera mitad del XIV.

Algunos de los tipos de lanza recuperados en Mendikute presentan, según el caso, claros paralelos con armas ofensivas similares de otros yacimientos contemporáneos peninsulares. Sin pretender ofrecer una relación exhaustiva de todos ellos, cabría mencionar algunos de los ejemplos mejor conocidos. En primer lugar, especialmente por su proximidad al área de estudio, debemos hacer mención de los ejemplares procedentes de la villa fortificada de Rada (Navarra). Las cinco piezas descubiertas en las excavaciones de este despoblado de la Baja Navarra, que aparece mencionado documentalmente en el siglo XII y cuya destrucción se produce en 1455 (Tabar, 1992: 381-385) presentan una morfología cercana a los ejemplares pertenecientes al tipo D de Mendikute, especialmente por lo que hace referencia a su tecnología de fabricación.

Se trata de puntas con hojas de gran porte y formas diversas, aunque todas ellas de sección romboidal hueca, con pronunciadas aristas axiales y enmangue tubular o cónico, que se dispone por lo general como una prolongación de las nervaduras laterales. En este conjunto predominan las hojas triangulares, con filos curvos más o menos pronunciados sobre la base y de anchura variable, de modo que el aspecto general de la pieza se aproxima, en ocasiones, a una forma cercana a la hoja de laurel o en otras a una hoja de sauce (Tabar 1992: 384-388). Los ejemplares publicados fueron localizados en tres habitaciones del despoblado, por lo que se datan en la primera mitad del siglo XV, aunque la autora matiza la probabilidad de que pudieran atribuirse al siglo XIV.

Las excavaciones del castillo de Monségur, célebre por el sitio y la capitulación de 1244 en el episodio cátaro, nos ofrece entre el armamento un ejemplar incompleto de punta de lanza, inventariado con el número 55/67, de características similares a los ejemplares del tipo A de Mendikute (GRAME, 1980: 112-113). En este caso, la hoja triangular, con filos curvos en la base y nervaduras axiales presenta sobre la base del enmangue cónico una perforación o abismal para su fijación al asta. Las dimensiones de este ejemplar incompleto datado del siglo XIII (de unos 150 de longitud estimada, 49 de anchura y $27 \mathrm{~mm}$ de diámetro) parecen ajustar, sin demasiados problemas con el tipo anteriormente mencionado.

Otros paralelos cercanos al tipo A se registran, por ejemplo, en el castillo de Alarcos, en el contexto de la batalla de 1195. Destacan por su parentesco las puntas de hojas triangulares de grandes dimensiones (Zozaya, 1995: 183, núm. 11), pero sobre todo la forma que A. Soler del Campo identifica como la punta de lanza conocida por el sobrenombre de "Azcona" (Zozaya, 1995: 181, núm. 9). Aunque en aquel caso, el ejemplar presenta unas proporciones ligeramente mayores que las lanzas del tipo A de Mendikute. Estos modelos de lanza parecen ser habituales en contextos del siglo XII, una pieza de parecidas características a las de Alarcos y de cronología coetánea se recuperó en las excavaciones de la alcazaba de Mértola (Barroca y Gouveia, 2000: 352, núm. 73).

Por lo que respecta al tipo E de Mendikute existen, en apariencia, menos referencias disponibles. Una pieza piramidal, de sección cuadrada y enmangue tubular, de parecidas características y dimensiones procedente del castillo de Alenquer (Portugal), aunque con una cronología no muy precisa, se halla depositada en el Museu Hipólito Cabaço (Barroca y Gouveia, 2000: 359, núm. 82). 
Sin embargo, sorprende advertir que algunos de los tipos que encontramos en Mendikute, especialmente las formas a modo de hoja de sauce (Tipos B y C), así como las puntas piramidales (tipo E) recuerdan inevitablemente a precedentes más antiguos. El armamento recuperado en algunas necrópolis merovingias cispirenaicas -Pamplona, Buzaga (Elorz, Navarra), Fínaga (Basauri, Vizcaya); San Pelayo (Alegria-DUlantzi, Álava)- ofrece algunos ejemplos de formas similares que son especialmente evidentes en el caso de la necrópolis de Aldaieta (Nanclares de Gamboa, Álava). Algo más lejos, en el asentamiento visigodo de Puig Rom (Girona) contamos con otro paralelo en forma de hoja de sauce (García y Vivó, 2003: 180). Estos materiales, cuya cronología parece situarse en torno a los siglos VI y VII, presentan claras similitudes frente a los materiales de plena época medieval de Mendikute.

Por ejemplo, la sepultura B12 de Aldaieta proporciona una punta de lanza (1204), que apareció situada sobre el bajo vientre de la inhumación, cuyas características y dimensiones se asemejan al tipo E de Mendikute (Azkarate 1999: 165). Del mismo modo, otras piezas como la del enterramiento A9 (561) o A1 (443) ofrecen un aspecto similar al tipo C de Mendikute, bien es verdad que, en aquel caso, las secciones de la hoja tienden a ser de forma losángica frente a nuestras formas predominantes (Azkarate, 1999: 102, 126). En suma, parece evidente que, pese a las analogías propias de este tipo de armamento, cuyas formas perduran a lo largo de la época medieval, podemos afirmar que las formas de Mendikute estuvieron en pleno uso a lo largo del siglo XIII y principios del siglo XIV en Guipúzcoa.

El armamento ofensivo altomedieval estaba compuesto, en esencia, por espadas, lanzas y arquería, pero desde mediados del siglo XI se producen cambios sustanciales ante la generalización del caballo y el nuevo uso dado a las lanzas, que constituyen el armamento ofensivo fundamental en el XIV en distintos territorios (Cantos, 2017). La espada recta, de doble filo y canal central predomina entorno a los siglos centrales de la edad media, aunque en el caso de Mendikute no ha aparecido ningún ejemplar de estas características. Sin embargo, junto a aquellas espadas de grandes proporciones se empieza a documentar, a partir de finales del siglo XII, el uso de espadas cortas o cuchillos de un solo filo. Este hecho, que aparece perfectamente documentado en los niveles de batalla de Alarcos, con ejemplares de 40-50 cm de longitud podría vincularse a un tipo de arma blanca específica de la infantería (Barroca y Gouveia, 2000: 25).

Estos ejemplares, cuyos precedentes se remontan al tipo de espada tardoantigua conocido como scramasax, parece haber sido el de uso más habitual entre los componentes de la guarnición de Mendikute. Los cuatro fragmentos de daga o espada corta recuperados en la excavación nos han permitido conocer las características esenciales de esta arma. Asimismo, el repertorio bélico de Mendikute también cuenta con algunos elementos auxiliares como los ganchos para armar la ballesta. Formas análogas a los ejemplares de Mendikute se documentan la Europa Mediterránea. Tal es el caso, por ejemplo, de los dos ejemplares recuperados en las excavaciones de Rougiers (Var). En aquel caso, los ejemplares presentan un mejor acabado, pero se fechan en un periodo similar a las piezas de Mendikute.

Esta forma simple de gancho parece corresponder con las primeras referencias documentales que se registran en Provenza desde mediados del siglo XIII, siendo utilizadas ampliamente durante la primera mitad del siglo siguiente, momento en el que el gancho de horna o doble gancho hace su aparición (Démians d'Archimbaud, 1980: 447). Sin embargo, es curioso advertir que este accesorio de la ballesta no aparece representado en los conjuntos armamentísticos más destacados de la península, a pesar de que en ellos existen pruebas arqueológicas suficientes para justificar el uso de la ballesta.

En este caso, no se ha documentado la presencia de ninguna nuez de ballesta, ni identificado ningún otro elemento metálico vinculado con claridad a este artefacto ofensivo. Las primeras noticias sobre el uso de ballestas en la península se remontan al siglo X y XI, pero no será hasta el siglo XII cuando se produzca la verdadera difusión de esta arma. Diversos ejemplares 
de nueces de ballesta de época almohade, procedentes de Calatrava la Vieja y de Alarcos, así como de los castillos alicantinos de Jijona y Alcoy, descritos por R. Azuar, constituyen la prueba arqueológica de la difusión del arma en contextos del siglo XII y principios del XIII (Zozaya, 1995: 187, núm. 15). Piezas similares aparecen en el ámbito portugués, por ejemplo en la alcazaba de Mértola, en un contexto del siglo XI o primera mitad del XII o en las excavaciones del convento de San Francisco de Santarém, entre los materiales de colmatación de un silo islámico, cuyo abandono se fecha en el siglo XI (Barroca y Gouveia, 2000: 117-118, 382-383).

\section{CONCLUSIONES}

La fortaleza de Mendikute presenta un repertorio de materiales interesante para el estudio de las prácticas bélicas en época bajomedival. En un contexto fronterizo de conflicto intermitente entre los reinos de Navarra y Castilla, el territorio guipuzcoano contó con guarniciones permanentes destacadas en fortificaciones como las de Mendikute y Ausa Gaztelu, entre otras, excavadas en un proyecto de intervención arqueológica realizado durante los años noventa. Esta línea defensiva, cuyo origen puede remontarse hasta el siglo XI, se mantuvo activo y con sus fortalezas en uso al menos hasta principios del XIV.

Las excavaciones arqueológicas han dado a conocer un nutrido conjunto de materiales metálicos, entre los que se cuentan abundantes elementos de carácter bélico como puntas de flecha, ballesta y lanza y otros elementos no proyectiles como las dagas, además de enseres auxiliares. Un análisis morfométrico detallado de los materiales recuperados en Mendikute nos ha permitido elaborar un estudio tipológico de dichos materiales, que cuentan además con numerosos paralelos en la Península Ibérica y el mediodía francés.

A lo largo de este trabajo hemos presentado de forma monográfica los principales rasgos identificados para el material bélico de Mendikute, junto con su interpretación cronológica y funcional, en una propuesta metodológica fundamentada en la objetivación de parámetros morfométricos analizados como variables a fin de definir con precisión los principales rasgos de los tipos determinados. En conjunto hemos puesto al alcance de los investigadores una colección que puede servir como referencia y paralelo para otros conjuntos coetáneos y que revisa de forma sumaria los principales elementos conocidos en los territorios adyacentes.

\section{BIBLIOGRAFÍA}

Álvaro, K. y Travé, E. (2019): «Los materiales arqueológicos de la fortaleza de Mendikute, Gipuzkoa (s. XII-XIV): elementos para el estudio de la vida cotidiana en un asentamiento militar». Munibe Antropologia-Arkeologia, 70: 319-334. https://doi.org/10.21630/maa.2019.70.09

Álvaro, K.; Travé, E. y López, M. D. (2017): «Los dados de Ausa y Mendikute (s. XIII-XIV): La elaboración de objetos lúdicos en hueso en algunas fortificaciones medievales del territorio guipuzcoano». Munibe Antropologia-Arkeologia, 68: 273-288. https://doi.org/10.21630/maa.2017.68.12

Arocena, F. (1957): El castrum Montis Acuti documentado como medieval. San Sebastián, Boletín de la Real Sociedad Vascongada de los Amigos del País, Año XIII, cuaderno 3.

Azkarate, A. (1999): Necrópolis tardoantigua de Aldaieta (Nanclares de Gamboa, Álava). Volumen I. Memoria de la excavación e inventario de los hallazgos. Vitoria-Gasteiz, Diputación Foral de Álava.

Barandiarán, I. (1970): «Excavaciones en Aiztzorrotz, 1968». Munibe, 3-4: 125-164.

Barker, P. C. (1975): «An exact method for describing metal weapon points», S. Laflin (ed.), Computer Applications in Archaeology 1975. Proceedings of the Annual Conference organised by the Computer Centre University of Birmingham, January 1975. Birmingham, Computer Centre, University of Birmingham: 3-8. 
Barrena, E. (1989): La formación histórica de Gipúzcoa. San Sebastián, Ed. Cuadernos Universitarios, 5.

Barroca, M. J. y Gouveia, J. (coord.) (2000): Exposición pera guerrejar. Armamento Medieval no Espaço Português. Palmela, Câmara Municipal de Palmela.

Cantos, A. (2017): «El armamento y sus innovaciones en el Aragón de la segunda mitad del siglo XIV». Revista Universitaria de Historia Militar, 6/11: 109-135.

Démians d'Archimbaud, G. (1980): Les Fouilles de Rougiers. Contribution a l'Archéologie de l'habitat rural médiéval en pays méditerranéen. Publication de l'U.R.A, 6. Archéologie médiévale méditerranéenne, Mémoires, 2. París, Éditions du CNRS.

García, F. (2016): «Combatir en la Península Ibérica medieval: Castilla-León, siglos XI al XIII. Estado de la cuestión». Imago Temporis Medium Aevum, 10: 383-407.

García, G. y Vivó, D. (2003): «Sant Julià de Ramis y Puig Rom: Dos ejemplos de yacimientos con armamento y equipamiento militar visigodo en el noreste peninsular». Gladius, XXIII: 161-190. https://doi.org/10.3989/gladius.2003.49

González, M. (2007): «Un conjunto de puntas de proyectil recuperadas en la excavación del Castro de los Judíos (Puente Castro, León) y el uso de arcos y ballestas en la edad media». Estudios Humanísticos. Historia, 6: 65-84.

González, M. (2012): «El castillo de Corullón: Estudio de un conjunto de proyectiles en el contexto de las revueltas irmandiñas». Gladius, XXII: 121-138. https://doi.org/10.3989/gladius.2012.0007

González, M. (2013): «El armamento de un asentamiento fortificado a finales del siglo XII: El Castro de los Judíos (Puente Castro, León)». Miscelánea Medieval Murciana, 37: 121-138.

GRAME, Groupe de Recherches Archéologiques de Montségur et Environs. (1980): «Montségur, 13 ans de Recherche Archéologique». Numéro spécial de La Recherche archéologique à Montségur : bulletin du groupe de recherches archéologiques de Montségur.

Ledesma, R. E. (2003): «Diseño de puntas de proyectil. Una vía de análisis alternativo para el estudio de identidad en la Quebrada del Toro, Provincia de Salta, Argentina». Cuadernos de la Facultad de Humanidades y Ciencias Sociales de la Universidad de Jujuy, 20: 241-269.

Mitxelena, K. (1953): Apellidos vascos. San Sebastián, Biblioteca Vascongada de los Amigos del País.

Orton, C. (1988): Matemáticas para arqueólogos. Madrid, Alianza.

Padilla, J. I. (1993): «Fortaleza Medieval de Mendikute (Albiztur). I Campaña de excavaciones». Arkeoikuska, 92: 211-227.

Padilla, J. I. (1994): «Fortaleza Medieval de Mendikute (Albiztur). II Campaña de excavaciones». Arkeoikuska, 93: 197-213.

Padilla, J. I. (1995): «Fortaleza Medieval de Mendikute (Albiztur). III Campaña de excavaciones». Arkeoikuska, 94: 185-203.

Padilla, J. I. (1996): «Fortaleza Medieval de Mendikute (Albiztur). IV Campaña de excavaciones». Arkeoikuska, 95: 189-211.

Padilla, J. I. (1997): «Fortaleza Medieval de Mendikute (Albiztur). IV Campaña de excavaciones». Arkeoikuska, 96: 99-107.

Rénoux, G.; Dabosi, F. y Lavaud, P. (2009): «Contribution a l'histoire des techniques et de l'armement : Essais de restitution du forgeage de pointes de flèche à partir de barres de fer d'époque antique». Gladius, XXIX: 39-70. https://doi.org/10.3989/gladius.2009.215

Serdon, Valerie (2005): Armes du diable. Arcs et arbalètes au Moyen Age. Rennes, Presses Universitaires de Rennes.

Tabar, I. (1992): «Puntas de lanza de época medieval procedentes de Rada». Trabajos de arqueología navarra, 10: 381-388.

Ubieto, A. (1963): Cartulario de San Juan de la Peña. Valencia, Anubar, Textos medievales, 9.

Zozaya, J. (coord.) (1995): Alarcos. El fiel de la Balanza. Toledo, Junta de Comunidades de Castilla-La Mancha. Col. Patrimonio Histórico, 15.

Recibido: 08-07-2019

Aceptado: 03-06-2020 